\title{
NUMERICAL MODELING OF TSUNAMI-INDUCED HYDRODYNAMIC FORCES ON ONSHORE STRUCTURES USING SPH
}

\author{
Philippe St-Germain ${ }^{1}$, Ioan Nistor ${ }^{2}$ and Ronald Townsend ${ }^{3}$
}

\begin{abstract}
In this paper, the simulation of the violent impact of tsunami-like bores with a square column is performed using a single-phase, weakly compressible three-dimensional Smoothed Particle Hydrodynamics (SPH) model. In order to avoid large fluctuations in the pressure field and to obtain accurate simulations of the hydrodynamic forces, a Riemann solver-based formulation of the SPH method is utilized. Large-scale physical experiments conducted by the authors are reproduced using the numerical model. Time-histories of the water surface elevation as well as timehistories of the pressure distribution and net total force acting on the column are successfully compared. As observed in previous breaking wave impact studies, results show that the magnitude and duration of the impulsive force at initial bore impact depend on the degree of entrapped air in the bore-front. Although ensuring a stable pressure field, the Riemann solver-based SPH scheme is believed to induce excessive numerical diffusion, as sudden and large water surface deformations, such as splashing at initial bore impact, are marginally reproduced. To investigate this particular issue, the small-scale physical experiment of Kleefsman et al. (2005) is also considered and modeled.
\end{abstract}

Keywords: SPH method; tsunami; bore-structure interaction; air entrainment; hydrodynamic forces

\section{INTRODUCTION}

During this past decade, the two largest natural disasters in the history of human kind, the 2004 Indian Ocean Tsunami (the deadliest disaster in the history of human kind) and the 2011 Japan Tsunami (the costliest one), have hit densely populated coastal areas. Following such catastrophic events, field reconnaissance missions in which the authors participated (CAEE Reconnaissance Team Indonesia and Thailand - 2005, Chile - 2010, and ASCE Reconnaissance Team Tohoku - 2011) revealed that current design codes do not provide appropriate guidelines for the design of inland structures against tsunamiinduced hydrodynamic loading (Nistor et al., 2009). Therefore, a novel interdisciplinary hydraulicstructural engineering research program was initiated at the University of Ottawa, Canada, in collaboration with the Canadian Hydraulic Centre of the National Research Council of Canada with the ultimate goal of providing practicing engineers with recommendations and appropriate design guidelines for structures at risk of such extreme hydrodynamic loading. Based on observed analogies between tsunami-induced bores and dam-break waves (Chanson, 2006), dam-break hydraulic bores of high velocity were experimentally generated (Nistor et al., 2010) in order to reproduce tsunami-like hydrodynamic loading on slender structural elements such as columns. This paper presents results of the numerical simulation of these physical experiments using a single-phase weakly compressible threedimensional SPH model. The final goal is to verify the applicability of the Smoothed Particle Hydrodynamics (SPH) method for the reproduction of such violent bore-structure impacts.

SPH is a mesh-free, Lagrangian particle method in which the state of a system is represented by a set of arbitrarily distributed particles, which possess individual material properties (i.e. position, velocity, mass, density, pressure, etc.) and move through the computational domain according to governing conservation equations. The discretization of the governing equations relies on approximating functions at one particle using a weighted average, or smoothening, of the properties of its neighboring particles. Since the formulation of the SPH method is not affected by the arbitrariness of the spatial distribution of the particles, the method is known to handle problems with large surface deformations without any special free-surface treatment. This is generally considered to be its most attractive feature. The method was first introduced in the late seventies by Gingold and Monaghan (1977), and by Lucy (1977) independently, in order to model astrophysical problems. Within the field of CFD, it was in the early nineties that the method was first considered to simulate free-surface flows (Monaghan, 1994).

In regards to bore-structure interactions, the SPH method was first used by Gómez-Gesteira and Dalrymple (2004) to simulate the impact of bores with a tall free-standing structure. They reproduced the physical experiment performed by Yeh and Petroff (n.d.) where a dam-break wave impacted a square column with a side dimension of $0.12 \mathrm{~m}$ inside a $1.60 \mathrm{~m}$ long $\times 0.61 \mathrm{~m}$ wide $\times 0.75 \mathrm{~m}$ deep

\footnotetext{
${ }^{1}$ Dpt. of Civil Eng., U. of Ottawa, 161 Louis-Pasteur, Ottawa, Ontario, K1N6N5, Canada, pstge055@uottawa.ca

${ }^{2}$ Dpt. of Civil Eng., U. of Ottawa, 161 Louis-Pasteur, Ottawa, Ontario, K1N6N5, Canada, inistor@uottawa.ca

${ }^{3}$ Dpt. of Civil Eng., U. of Ottawa, 161 Louis-Pasteur, Ottawa, Ontario, K1N6N5, Canada, townsend@eng.uottawa.ca
} 
rectangular tank (upstream reservoir impoundment depth $h_{u}=0.30 \mathrm{~m}$ ). The same set of experimental data was later reproduced by Silvester and Cleary (2006) in a study where a sensitivity analysis of various SPH simulation parameters was conducted. By simulating the physical experiment of Kleefsman et al. (2005), Lee et al. (2010) compared a weakly compressible formulation with a truly incompressible formulation of the SPH method. Once again, this experiment was performed to investigate the impact of a dam-break wave with a $0.16 \mathrm{~m}$ long $\times 0.40 \mathrm{~m}$ wide $\times 0.16 \mathrm{~m}$ high rectangular obstacle within a $3.22 \mathrm{~m}$ long $\times 1.00 \mathrm{~m}$ wide $\times 1.00 \mathrm{~m}$ deep rectangular tank $\left(h_{u}=0.55 \mathrm{~m}\right)$. Their results showed that a weakly compressible SPH model (WCSPH), similar to the one considered in this study, would yield an inaccurate and highly-fluctuating pressure field compared to a truly incompressible SPH model (ISPH). In addition, they also observed that the splash at initial impact of the dam-break wave with the obstacle was much more realistic in their ISPH simulation. This was due to the fact that the intensity of this splash was significantly underestimated in their WCSPH simulation. By using a Shepard density filter to reduce fluctuations in the pressure field along with a relatively high particle resolution, Crespo et al. (2011) reproduced the same physical experiment using a WCSPH model. The latter simulation, which was performed on the GPU, resulted in both accurate pressure results and realistic splashing at initial impact. The reader is referred to Gómez-Gesteira et al. (2010a) for details on density filters. Other studies (Hughes and Graham, 2010; Shadloo et al., 2011) have also compared WCSPH and ISPH models and have shown that both approaches can generate similar results. Finally, due to the relatively small size of the bores and the presence of a wall just downstream of the impacted structures that caused wave reflection, the experiments of Yeh and Petroff (n.d.) and Kleefsman et al. (2005) did not realistically reproduced the impact of tsunami bores on structures. Hence, realistic timehistories of hydrodynamic forces resulting from the extended action of tsunami bores were not obtained.

With the objective to better understand the interaction of tsunami bores with slender structural components such as individual columns, the current paper presents a portion of the laboratory results obtained within the aforementioned interdisciplinary research program (Nistor et al. 2010). These physical results are reproduced using a single-phase three-dimensional WCSPH numerical model. In addition, the physical experiment of Kleefsman et al. (2005) is also reproduced in order to investigate difficulties in the numerical reproduction of sudden and violent deformation of the water surface (i.e. splashing at initial bore impact with structure). First, brief descriptions of the physical experimental settings are provided and subsequently, the related computational domains are described. Afterwards, time-histories of the water surface elevation as well as time-histories of the pressure distribution and net force acting on the test structures are qualitatively compared.

\section{EXPERIMENTAL SETUPS}

Nistor et al. (2010)

These physical experiments were performed by the authors at the Canadian Hydraulics Centre of the National Research Council of Canada (NRC-CHC), in Ottawa, Canada. Dam-break hydraulic bores were generated in a $10.85 \mathrm{~m}$ long $\times 1.3 \mathrm{~m}$ wide $\times 1.4 \mathrm{~m}$ deep stainless steel flume using water impounded and released by means of a swinging gate mechanism installed such that a $5.6 \mathrm{~m}$ long $\times 2.7 \mathrm{~m}$ wide $\times$ $1.4 \mathrm{~m}$ deep partitioned reservoir was created upstream. Runs were performed with impoundment depths $\left(h_{u}\right)$ of $0.55,0.85$, and $1.15 \mathrm{~m}$. A square Plexiglas column with side dimension of $0.30 \mathrm{~m}$ and a height of $1.00 \mathrm{~m}$ was located $4.92 \mathrm{~m}$ downstream of the gate. After impacting the column, water was evacuated through a floor drain located $2.65 \mathrm{~m}$ further downstream. Fig. 1 shows a schematic of the experimental setting. Although rubber water-stops were used around the gate assembly, due to the relatively large impoundment depths employed, minor leakages across the gate occurred. Due to the difficulty in

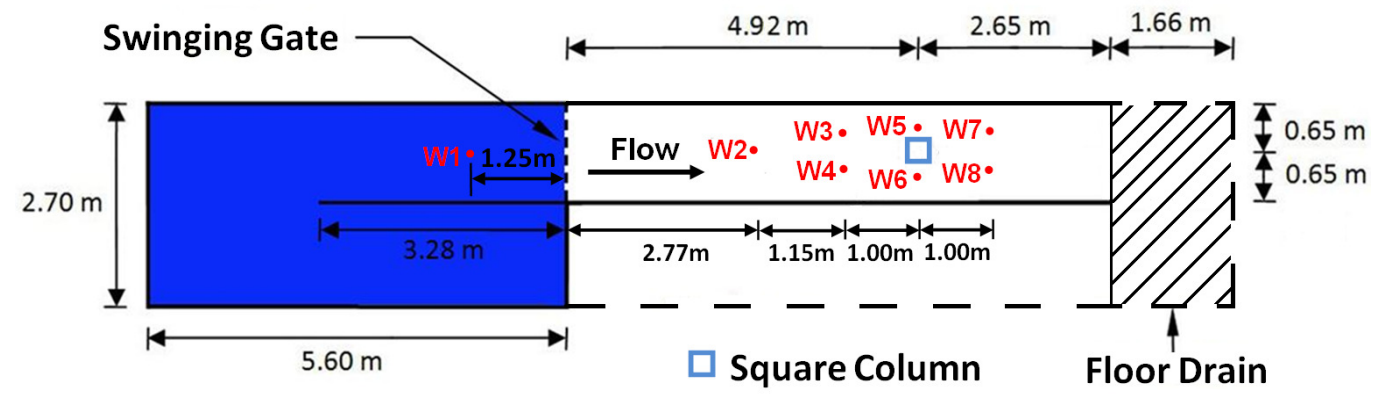

Figure 1. Plan view of the experimental setup of Nistor et al. (2010). 
completely drying the downstream section of the test channel between each run, most experiments were performed with a downstream water depth $h_{d} \approx 0.005 \mathrm{~m}$ (see Fig. 12-b). Runs performed with a "virtually" dry bed (see Fig. 12-a) were only achieved by allowing sufficient time between runs for the flume's bottom to dry. It should be noted that, for demonstrative purposes, Fig. 12 corresponds to experimental runs performed with a mitigation wall and these were not simulated with the numerical model in the current study.

The time-history of the water surface elevation was recorded using 13 wave gauges placed at various locations along the flume and on the sides of the column (denoted by "W" in Fig. 1 and Fig. 2). The time-history of the pressures exerted on the column were recorded using a single row of 10 pressure transducers (denoted by "P" in Fig. 2), aligned vertically at elevations of $0.05,0.10,0.20$, $0.25,0.30,0.35,0.40,0.45,0.50$, and $0.55 \mathrm{~m}$ above the flume's bottom. Finally, the time-history of the net total base horizontal force was recorded using a six degree of freedom dynamometer placed at the column's base (Fig. 2). The sampling rate of the measuring devices was $1,000 \mathrm{~Hz}$.

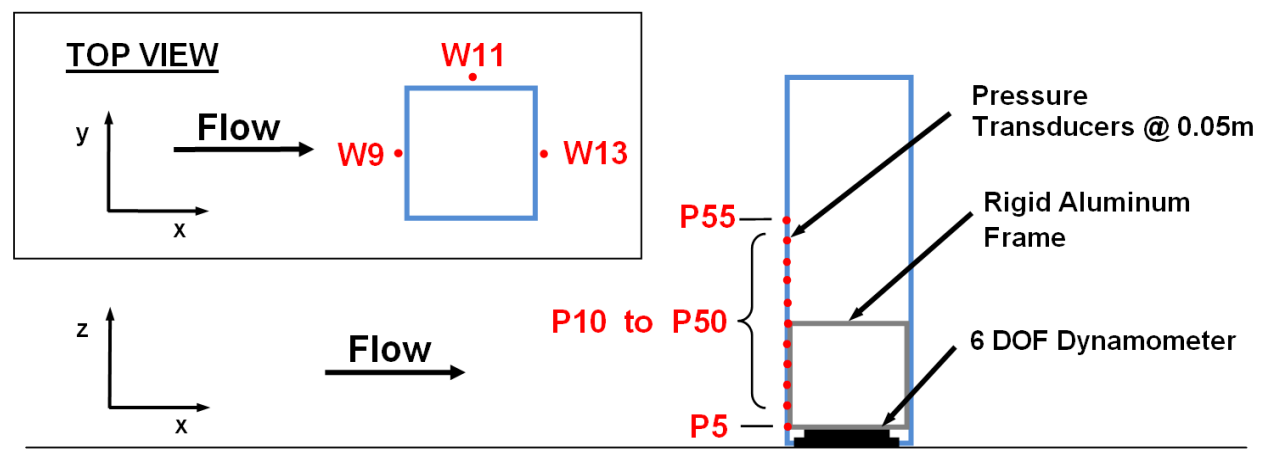

Figure 2. Schematic of experimental column model and instrumentation used by Nistor et al. (2010).

\section{Kleefsman et al. (2005)}

Performed at the Maritime Research Institute Netherlands (MARIN) and similar to the experiment of Yeh and Petroff (n.d.), this dam-break experiment was performed in a $3.22 \mathrm{~m}$ long $\times 1.00 \mathrm{~m}$ wide $\times$ $1.00 \mathrm{~m}$ deep rectangular tank with $h_{u}=0.55 \mathrm{~m}$ and $h_{d}=0$. However, rather than a tall slender column, the test structure was a short and relatively wide obstacle $(0.161 \mathrm{~m}$ long $\times 0.403 \mathrm{~m}$ wide $\times 0.161 \mathrm{~m}$ high $)$. This obstacle was located $1.248 \mathrm{~m}$ downstream of a vertical gate that was "instantaneously" raised by the release of weights. A schematic of the experimental setting is shown in Fig. 3.

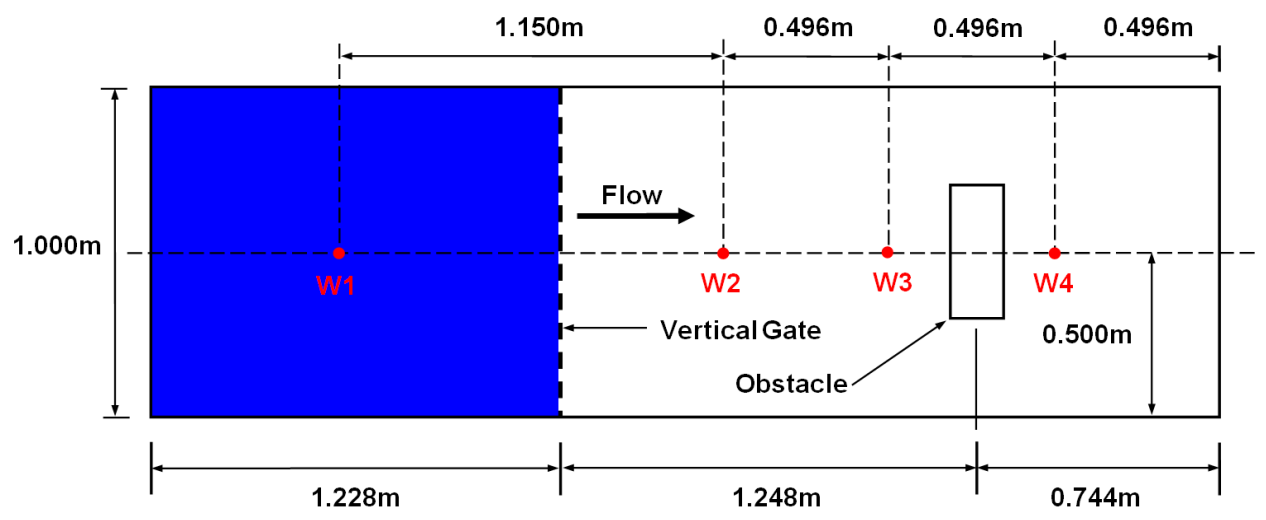

Figure 3. Plan view of the experimental setup of Kleefsman et al. (2005).

The time-history of the water surface elevation was recorded using four wave gages placed at various locations along the centerline of the experimental tank (denoted by "W" in Fig. 3). The timehistory of the pressure exerted on both the upstream and top faces of the obstacle was recorded using eight pressure transducers (denoted by "P" in Fig. 4). Data was obtained at a sampling rate of 1,000Hz. 


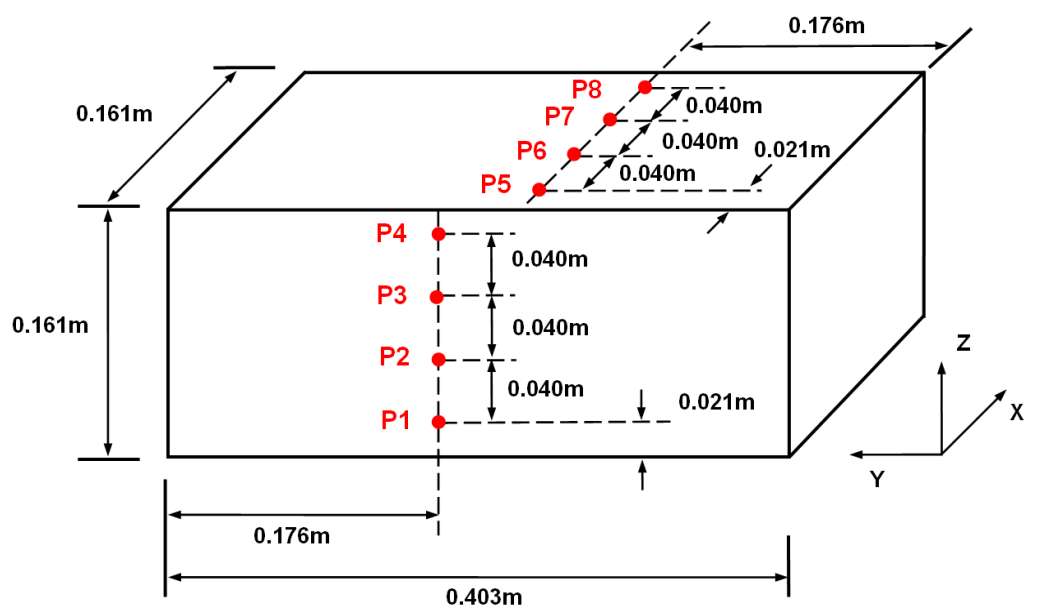

Figure 4. Test structure considered in the experiment of Kleefsman et al. (2005).

\section{COMPUTATIONAL DOMAINS}

Numerical simulations were performed using the SPHysics and ParallelSPHysics open source implementations (Gómez-Gesteira et al., 2010b). With regards to space limitation, the reader is referred to St-Germain et al. (2012) for comprehensive theoretical and computational details with respect to the SPH formulation mentioned below. Also, with the exception of the ones listed in the following subsections, all SPH-related parameters employed for the simulations presented in this paper are as provided in St-Germain et al. (2012).

To effectively calculate the pressure terms of the Navier-Stokes momentum equation without having to solve a cumbersome Poisson equation, the fluid is assumed to be weakly compressible and the equation of state, originally given by Batchelor (1967) and modified by Monaghan (1994), is used. Consequently, the compressible Navier-Stokes equation of continuity is considered. As reported in the literature, the resulting pressure field predicted by a WCSPH model will generally suffer considerably large fluctuations. To avoid such fluctuations, this study employs the adapted SPH formulation of Parshikov et al. (1999) for which a Riemann problem is considered for each particle interaction. This Riemann problem is solved using a Harten - Lax - van Leer - Contact (HLLC) approximate Riemann solver using a Monotone Upwind-centred Scheme for Conservation Laws (MUSCL) (Toro et al., 1994; Toro, 2001) with a general $\beta$-limiter (Hirsch, 1998).

For modeling the diffusion terms of the Navier-Stokes momentum equation, the laminar viscosity with Large Eddy Simulation (LES) type Sub-Particle Scale (SPS) turbulence model, proposed by Dalrymple and Rogers (2006), is used.

Lastly, the walls and bottom of the flume, along with the impacted structures, are formed of perfectly fixed boundary particles according to the repulsive boundary condition proposed by Monaghan and Kos (1999) and later modified by Rogers and Dalrymple (2008).

\section{Nistor et al. (2010)}

Due to the repulsive boundary condition considered, it was not possible to numerically reproduce the exact thickness of the thin water layer initially present in the physical experiment downstream of the gate, prior to its opening. This is because magnitude of repulsive forces exerted on the fluid particles by the boundary particles are too strong when compared to the hydrostatic force of the still fluid acting on the bottom of the channel. This results in fluid particles being repulsed to an elevation considerably higher than that occurring in the experiment $\left(h_{d} \approx 0.005 \mathrm{~m}\right)$. Consequently, unless mentioned otherwise, a dry-bed condition was assumed for the simulations in this paper.

In order to allow water particles to leave the computational domain once they reached the end of the channel, no downstream wall was considered. This way, the effect of the floor drain present in the physical model was accurately reproduced. The initial configuration of the computational domain is shown in Fig. 5. The experimental opening time of the gate was sufficiently short in order to generate a "sudden" dam-break according to the criterion of Lauber and Hager (1998). Hence, for simplicity, this gate was not considered in the numerical simulations and water in the numerical reservoir was instead instantaneously released. 


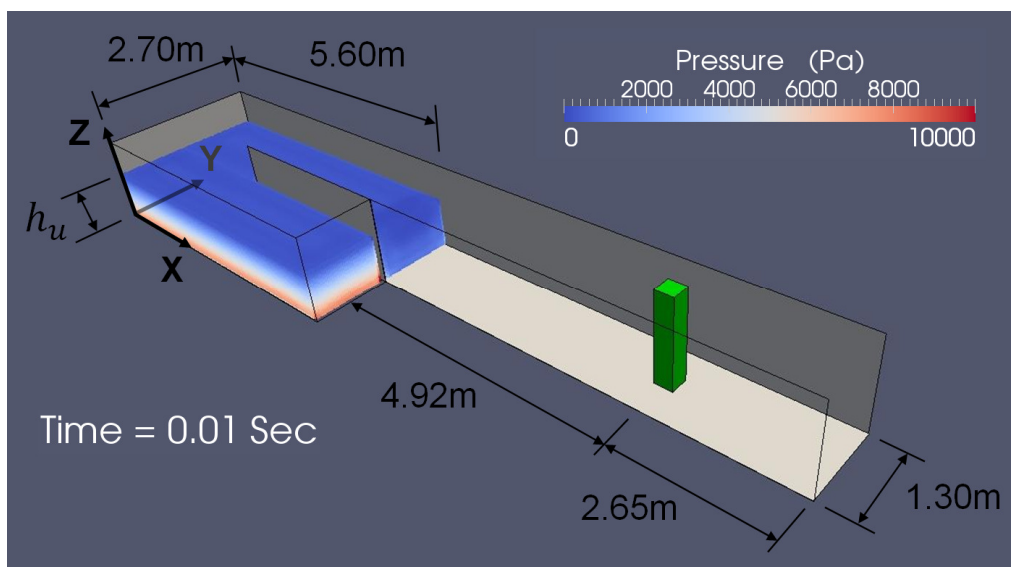

Figure 5. Initial configuration of the computational domain reproducing the experiments of Nistor et al. (2010).

In terms of SPH-related parameters, an initial inter-particle spacing $\Delta=0.035 \mathrm{~m}$ in all directions and a constant smoothing length $h=0.725\left(3 \Delta^{2}\right)^{1 / 2}=0.0440 \mathrm{~m}$ was used for all related simulations. As suggested by Monaghan (1994), and considering the maximum velocity of a dam-break wave to be approximately $\left(2 g h_{u}\right)^{1 / 2}$, the values of the speed of sound in water at the reference density $\left(c_{0}\right)$ used in the equation of state were selected as $12\left(2 g h_{u}\right)^{1 / 2}>10\left(2 g h_{u}\right)^{1 / 2}$. For each of the impoundment depths $\left(h_{u}\right)$ considered, Table 1 presents the resulting number of particles (including both the water and fixed boundary particles), the speed of sound $\left(c_{0}\right)$, and the computational times required to simulate 10 seconds of physical time on 32 parallel processors. For these simulations, note that the parallelized code ParallelSPHysics was utilized. Lastly, due to the limited hard disk memory, numerical outputs were obtained at a frequency of $100 \mathrm{~Hz}$ throughout the simulations. However, to ensure proper capture of sudden rises in the resulting force, a high sampling frequency of $1000 \mathrm{~Hz}$ was used over short intervals covering initial bore impact.

\begin{tabular}{|c|c|c|c|c|}
\hline \multicolumn{6}{|c|}{ Table 1. Details of numerical simulations corresponding to the experiments of Nistor et al. (2010). } \\
\hline Simulation & $\begin{array}{c}h_{u} \\
(\mathrm{~m})\end{array}$ & $\begin{array}{c}c_{0} \\
(\mathrm{~m} / \mathrm{s})\end{array}$ & Number of Particles & $\begin{array}{c}\text { Computational Time } \\
\text { (days) }\end{array}$ \\
\hline A-55 & 0.55 & 39.42 & 459,260 & 4.86 \\
A-85 & 0.85 & 49.00 & 654,648 & 6.94 \\
A-85-NC & 0.85 & 49.00 & 648,060 & 6.88 \\
A-115 & 1.15 & 57.00 & 849,580 & 10.42 \\
\hline
\end{tabular}

Kleefsman et al. (2005)

In the next comparison of numerical with physical results, some discrepancies in the reproduction of the sudden water splash at initial bore impact will be observed. To further investigate this issue, the resolution of the simulations was gradually increased by decreasing the initial inter-particle spacing $(\Delta)$. At the time of this exercise, the associated simulations were performed with the serial code SPHysics due to constraints in computing resources. Consequently, it was not possible to simulate the large-scale experiments of Nistor et al. (2010) within a manageable timeframe and hence the smaller experiment of Kleefsman et al. (2005) was simulated instead. Fig. 6 shows the initial configuration of the associated computational domain.

For each of the $\Delta$ employed, Table 2 presents the resulting number of particles (including both the water and fixed boundary particles), the smoothing length $(h)$, and the computational times required to simulate 6 seconds of physical time on one single processor. With the impoundment depth $h_{u}=0.55 \mathrm{~m}$ associated to the physical experiment of Kleefsman et al. (2005), the speed of sound in water at the reference density $c_{0}=12\left(2 g h_{u}\right)^{1 / 2}=39.42$. Lastly, numerical outputs were obtained at a frequency of $100 \mathrm{~Hz}$ for simulations B-0350 and B-0200, and $200 \mathrm{~Hz}$ for simulation B-0155.

\footnotetext{
${ }^{4}$ Simulation performed without the column structure.
} 


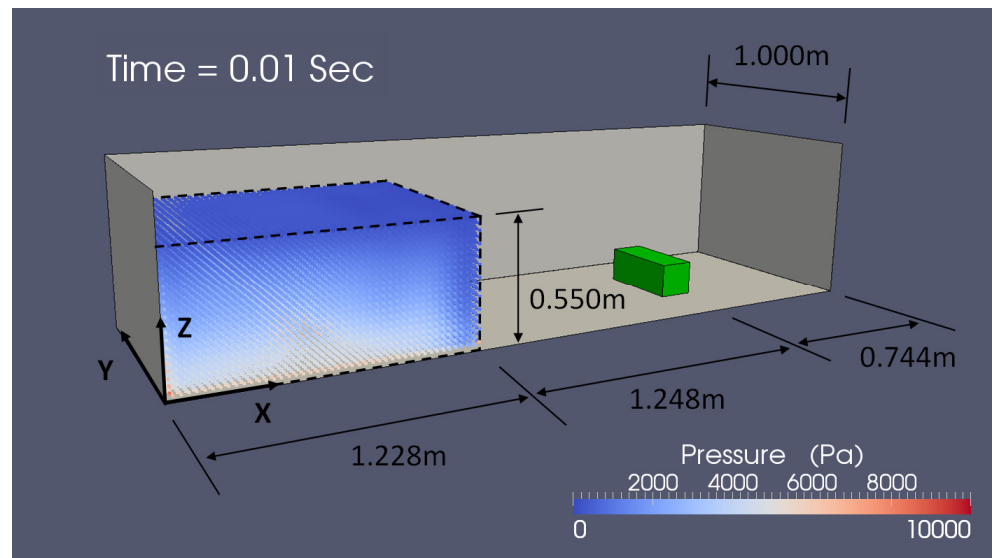

Figure 6. Initial configuration of the computational domain reproducing the experiment of Kleefsman et al. (2005).

\begin{tabular}{|c|c|c|c|c|}
\hline \multicolumn{5}{|c|}{ Table 2. Details of numerical simulations corresponding to the experiments of Kleefsman et al. (2005). } \\
\hline Simulation & $\begin{array}{c}\Delta \\
(\mathrm{m})\end{array}$ & $\begin{array}{c}h \\
(\mathrm{~m})\end{array}$ & Number of Particles & $\begin{array}{c}\text { Computational Time } \\
\text { (days) }\end{array}$ \\
\hline B-0350 & 0.0350 & 0.0440 & 77,690 & 2.92 \\
B-0200 & 0.0200 & 0.0251 & 192,060 & 9.24 \\
B-0155 & 0.0155 & 0.0195 & 397,412 & 29.25 \\
\hline
\end{tabular}

\section{COMPARISON OF NUMERICAL WITH PHYSICAL RESULTS}

\section{Nistor et al. (2010)}

Water surface elevation. Fig. 7 shows the numerical and experimental time-history of the water surface elevation at wave gauges W1, W2, W3, and W6 performed without the column structure and with an impoundment depth $h_{u}=0.85 \mathrm{~m}$. Although good agreement can generally be observed, it can be
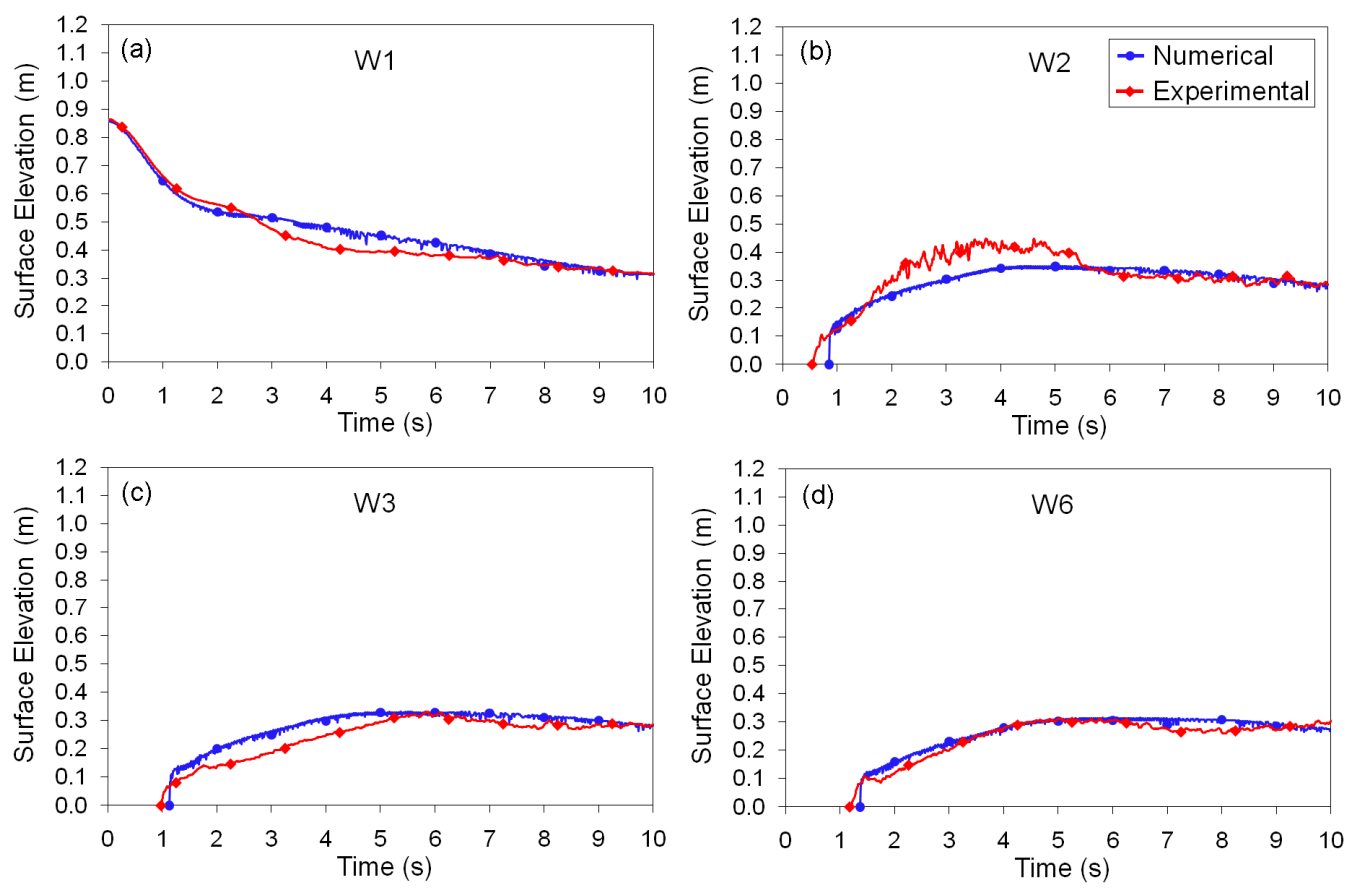

Figure 7. Comparison of numerical (simulation A-85-NC) and experimental time-history of the water surface elevation at wave gauges (a) W1, (b) W2, (c) W3, and (d) W6 for $h_{u}=0.85 \mathrm{~m}$ and without the column model. 
seen from Fig. 7-a that the experimental time-history at W1 dips momentarily below the numerical one. On the other hand, in the case of W2, the experimental time-history momentarily surpasses the one predicted by the numerical model. After analyzing the video of the physical experiments, it was noticed that small diagonal cross-waves not reproduced by the numerical model occurred near the location of W2, explaining the latter discrepancy.

Fig. 8 shows the numerical and experimental time-histories of the water surface elevation at wave gauge W9 for $h_{u}=0.85 \mathrm{~m}$. From hereafter, the water depth at W9 will be referred to as the "runup" of water on the upstream face of the column. The figure shows that a discrepancy occurs in the earlier

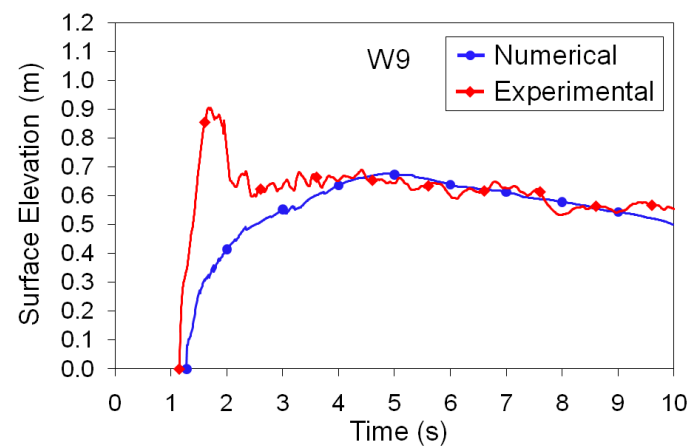

Figure 8. Comparison of numerical (simulation A-85) and experimental time-history of the water surface elevation at wave gauges W9 for $h_{u}=0.85 \mathrm{~m}$.

stages of the bore-structure interaction. This is because the numerical model does not accurately reproduce the significant splash of water occurring at initial impact. To show the latter, a visual comparison of still frames $\left(h_{u}=1.15 \mathrm{~m}\right)$ is provided in Fig. 9. Yet, later in the simulation, beyond approximately 3 seconds, the agreement in the runup (Fig. 8) and in the overall profile of the water surface within the vicinity of the column (Fig. 9-c and Fig.9-d) is fairly good. The lack of splashing at

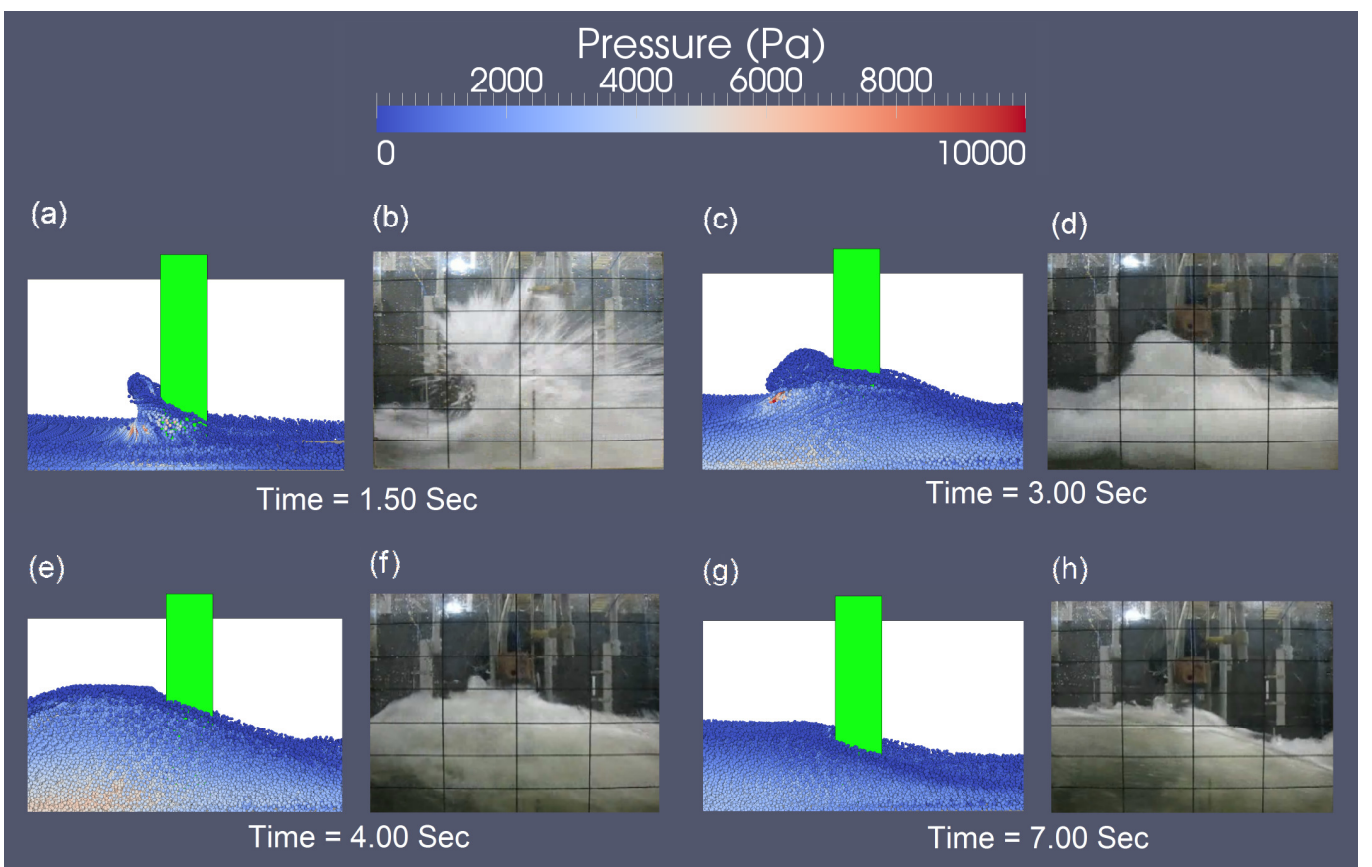

Figure 9. Qualitative comparison of numerical (left, simulation A-115) and experimental (right) water surface profiles (a, b) 1.50, (c, d) 3.00, (e, f) 4.00, and (g, h) 7.00 seconds after gate opening for $h_{u}=1.15 \mathrm{~m}$.

initial impact in the numerical simulation is believed to be due to the relatively coarse particle resolution in conjunction with the use of a Riemann solver (i.e., a Godunov-based scheme) for removing inaccuracies in the pressure field. According to Dr. Benedict Rogers (e-mail communication, 2012), one of the developers of SPHysics, the main side effect of this combination is excessive 
"numerical viscosity" or perhaps numerical diffusion, which would prevent the water particles from reaching higher elevations and separating from one another. As it will be demonstrated in the section of the paper considering the physical experiment of Kleefsman et al. (2005), increasing the particle resolution can help mitigate this detrimental side effect.

Exerted pressures. The comparison of the numerical and experimental time-histories of pressures acting at various elevations on the upstream face of the column is presented in Fig. 10 for $h_{d}=1.15 \mathrm{~m}$. Although good agreement is generally observed, the numerical prediction of the initial impact pressure at transducer P5 is much larger than the experimentally-measured one. A plausible explanation for this disagreement is provided shortly when the effects of the entrapped air in the experimental bore-front on the resulting force at the moment of impact are discussed.
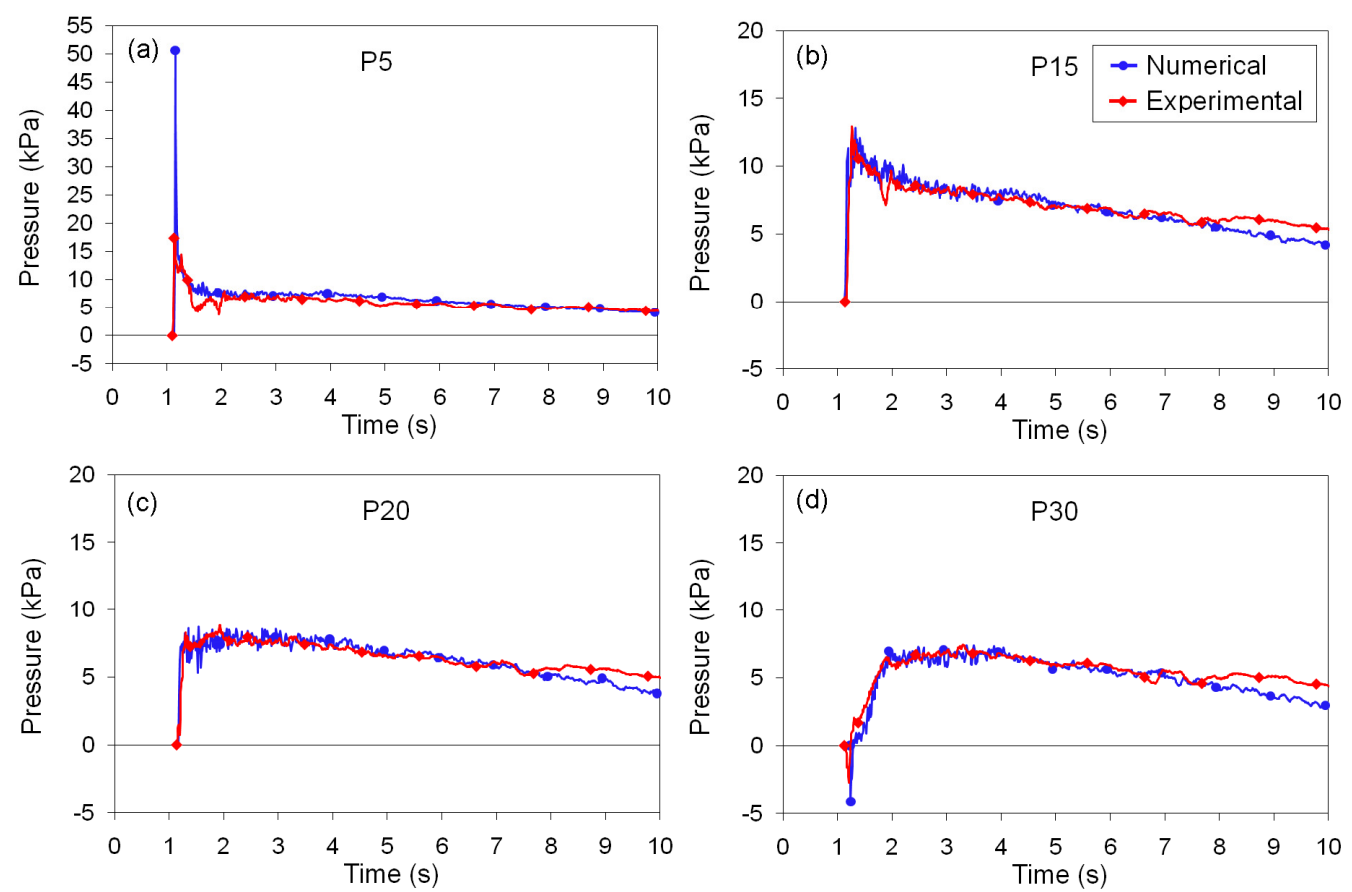

Figure 10. Comparison of numerical (simulation A-115) and experimental time-history of pressures acting on the column at elevations of (a) 0.05 , (b) 0.15 , (c) 0.20 , and (d) $0.30 \mathrm{~m}$ above the flume's bottom for $h_{u}=1.15 \mathrm{~m}$.

As shown in Fig. 10-d, the numerical model was capable of capturing the development of negative pressures which occurred at initial impact at higher elevations on the column. These negative pressures can be attributed to the water jet being reflected upstream, and the subsequent suction created as the water separates away from the column's face. In addition, a gradually increasing discrepancy can be observed towards the end of the simulation. This is because the computational domain did not consider the additional reservoir volume provided within the pipes that supply water to the experimental flume. This resulted in numerical bores of slightly shorter duration.

Net base horizontal force. By integrating the numerical pressure exerted on its entire surface, the numerical time-history of the net base horizontal force acting streamwise on the column was obtained. This was further compared with the experimentally-obtained one captured by the dynamometer. Fig. 11 shows this comparison for all impoundment depths, $h_{u}$. In the case of $h_{u}=0.55 \mathrm{~m}$, both the experimental dry- and wet-bed conditions are considered (Fig. 11-a and Fig. 11-b, respectively). All numerical timehistories of the force displays a distinctive peak at initial impact while most experimental ones do not, as they correspond to the wet-bed condition. This is further discussed below. Beyond initial impact and for all impoundment depths, the rate at which the force increases due to the runup of the bore on the column (i.e. the rising inundation level at the front of this one) is in perfect agreement up until the second peak is reached. This second peak in the time-history of the force is referred to as the "runup force". As the impoundment depth increases, this runup force occurs earlier. In the case of the numerical runup force, it also becomes more significant comparing to the initial impact force. Further on, the experimental time-history of the force shows large fluctuations which increases with the impoundment depth. Surprisingly, these fluctuations were not recorded in the experimental time-history 
of the pressures exerted on the upstream face of the column (Fig.10). Hence, these could be due to an unsteady formation of the wake downstream of the column, as very strong turbulence and air entrainment was observed during the experimental runs. Finally, the fact that the numerical model does not account for air entrainment could possibly explain its inability to reproduce the fluctuations in the time-history of the force.
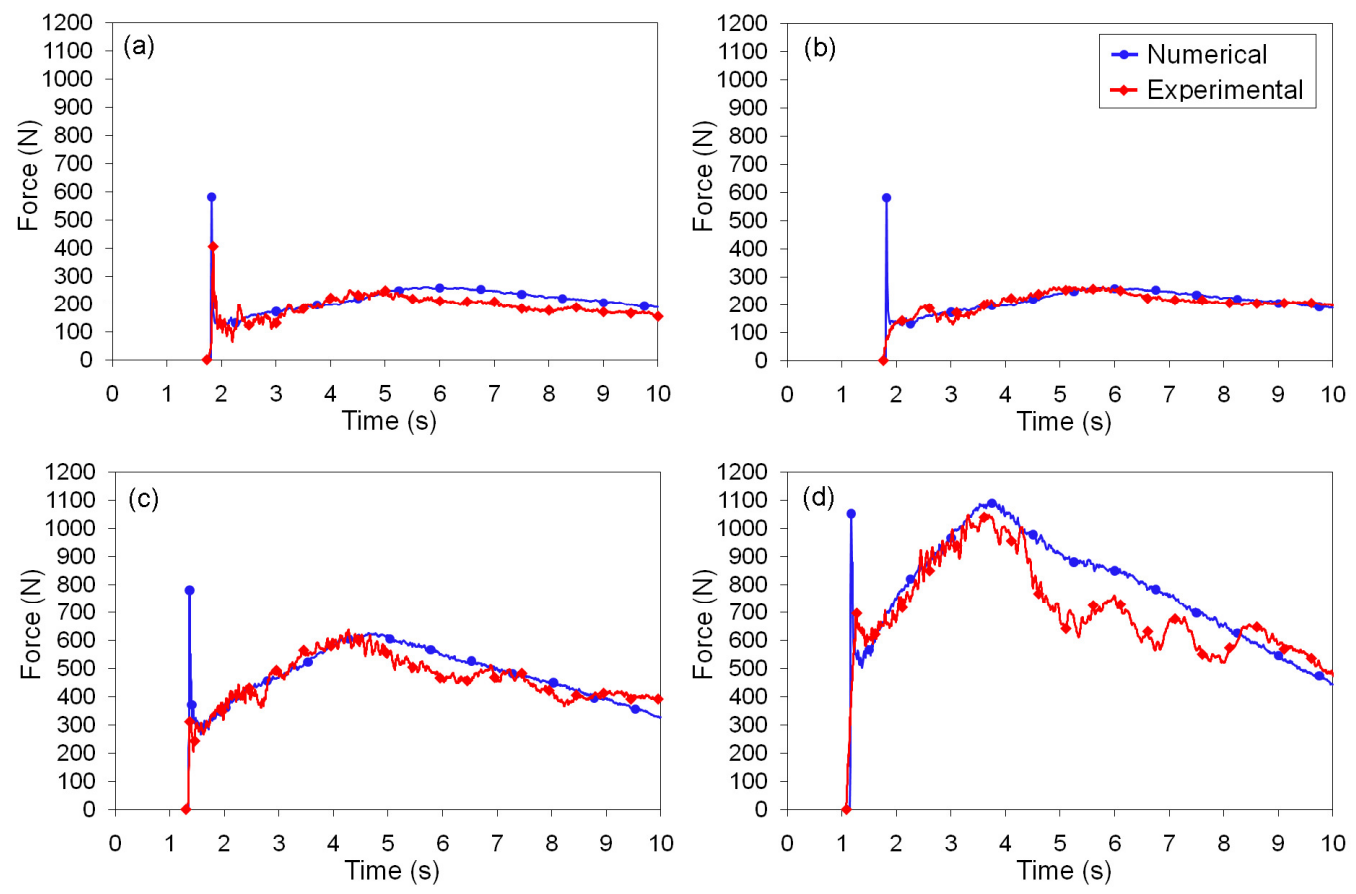

Figure 11. Comparison of the numerical and experimental time-history of the net total base horizontal force acting on the column for impoundment depths $\left(h_{u}\right)$ of $(a, b) 0.55 \mathrm{~m}$, (c) $0.85 \mathrm{~m}$, and (d) $1.15 \mathrm{~m}$. Experimental results in (a) correspond to dry-bed condition $\left(h_{d} \approx 0\right)$.

In the case of Fig.11-a, impulsive spikes are clearly visible at initial impact of the hydraulic bore with the column, indicating the occurrence of shock pressures. This is for both the numerical and experimental results, as both the associated experimental and numerical runs correspond to dry-bed condition. On the other hand, such spikes are not observed for the experimental runs performed with wet-bed condition (e.g. Fig. 11-b). In an experimental study focusing on the impact of ocean waves breaking directly on vertical walls, Hattori et al. (1994) found that the larger the amount of air entrapped in the impinging wave, the lower the magnitude and the longer the rise, or compression time of the impact pressures. This "cushioning" provided by the entrapped air and its effect on impact pressures was also noticed by Peregrine (2003), who also investigated experimentally the impact of breaking waves on vertical walls. Hence, the explanation for the absence of impulsive spikes in the force (i.e. shock pressures) at initial impact in the case of physical experiments performed with wet bed is as follows. As the hydraulic bore advances in the test channel, the still water layer resists to its propagation. This flow resistance and the resulting decrease in the bore-front velocity are well documented in the literature (Jánosi et al., 2004; Leal et al., 2006), even for $h_{d}$ of few millimeters. It is believed that the momentum transfer from the advancing bore-front to the downstream still water layer generates additional turbulence resulting in considerable air entrainment. Finally, it would be this higher concentration of entrapped air in the bore-front that inhibits shock pressures at initial impact. In fact, by comparing still images from the current physical experiments (Fig. 12), this increase in the concentration of entrapped air within the bore-front can be observed. Note that the actual runs shown in these figures were performed with a mitigation wall, and such protection measure is not considered in the current study.

Over a short time interval covering initial impact, Fig. 13-a shows the experimental time-history of net force acting on the column for both dry- and wet-bed conditions for $h_{u}=0.55 \mathrm{~m}$. The time required for the first distinct peak to be reached is 0.110 and 0.879 seconds for the dry- and wet-bed conditions, respectively. Hattori et al. (1994) noticed that the time required for air bubbles to compress increases 


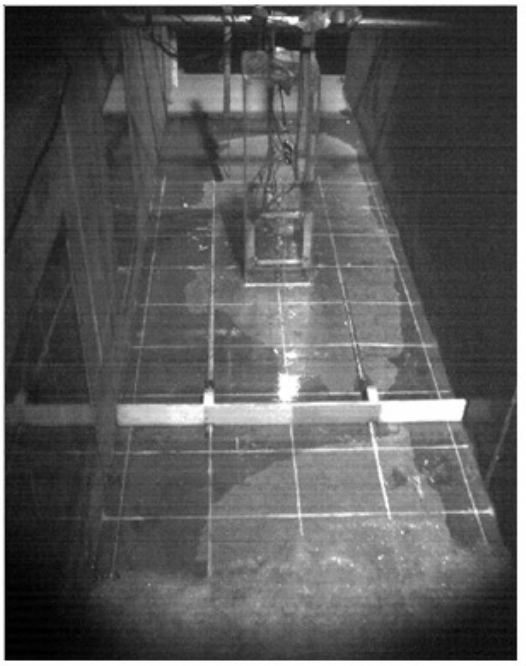

(a)

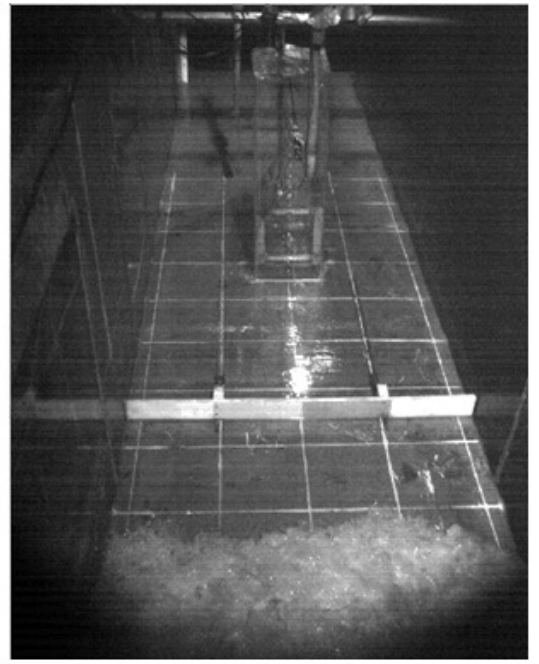

(b)

Figure 12. Experimental still frames of the bore-front propagating over (a) a "virtually" dry bed $\left(h_{d} \approx 0\right)$ and (b) a wet bed $\left(h_{d} \approx 0.005 \mathrm{~m}\right)$ with $h_{u}=0.55 \mathrm{~m}$.

the rise time. Hence, a rise time which is greater in the case of the wet-bed condition supports the aforementioned hypothesis which states that more air is entrapped in the bore-front as it propagates over a wet bed. Similarly, Fig. 13-b shows, over a short time interval covering initial impact, the comparison between the numerical and experimental time-history of the net total force acting on the column for an impoundment depth of $0.55 \mathrm{~m}$. The numerical results correspond to a run with a perfectly dry bed, while the experimental ones correspond to a run with a "virtually" dry bed, as previously discussed. It can be seen that the rise time of the force impulse at initial impact is longer in the case of the physical experiment ( 0.110 seconds compared to 0.029 seconds), which demonstrates that a minimal degree of air entrainment still occurs due to the friction with the experimental flume's "virtually" dry bottom. As the numerical model does not model the air phase, the predicted magnitude of the force impulse is therefore greater, as the cushioning effect of entrapped air bubbles generally reduces it (Peregrine, 2003).
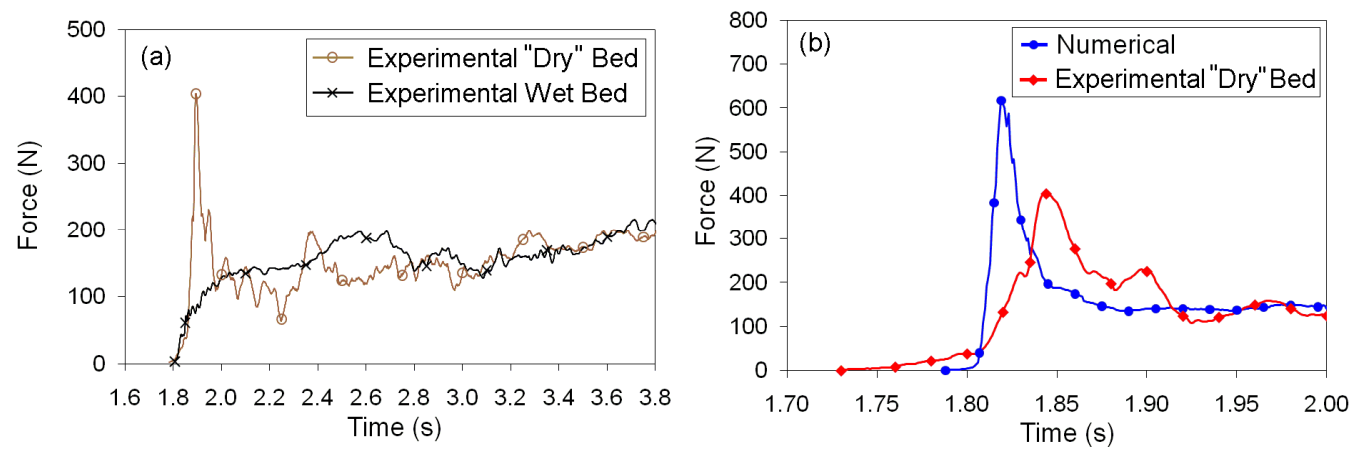

Figure 13. (a) Comparison of the experimental rise time of the net base horizontal force acting on the column due to the impact of bores $\left(h_{u}=0.55 \mathrm{~m}\right)$ propagating on dry $\left(h_{d} \approx 0\right)$ and wet $\left(h_{d} \approx 0.005 \mathrm{~m}\right)$ beds. (b) Comparison of the experimental and numerical (simulation A-55) rise time of the net base horizontal force acting on the column due to the impact of a bore $\left(h_{u}=0.55 \mathrm{~m}\right)$ propagating on a dry bed (numerical $h_{d}=0$ and experimental $h_{d} \approx 0$ ).

Although the amount of air entrapped in the bore-front was showed to have significant influence on the development of shock pressures and impulsive forces at initial impact, other variables, particularly the bore-front steepness, can also be of importance. As bores that propagates over a wet bed tend to be deeper and have a steeper front (Stansby et al. 1998). The numerical simulations of bores propagating on dry and wet beds were performed in St-Germain et al. (2012) and their resulting interaction with slender columns and infinitely wide vertical walls was studied. For instance, Fig. 14 demonstrates the influence of the bed condition on the bore profile before impact with a square column. 


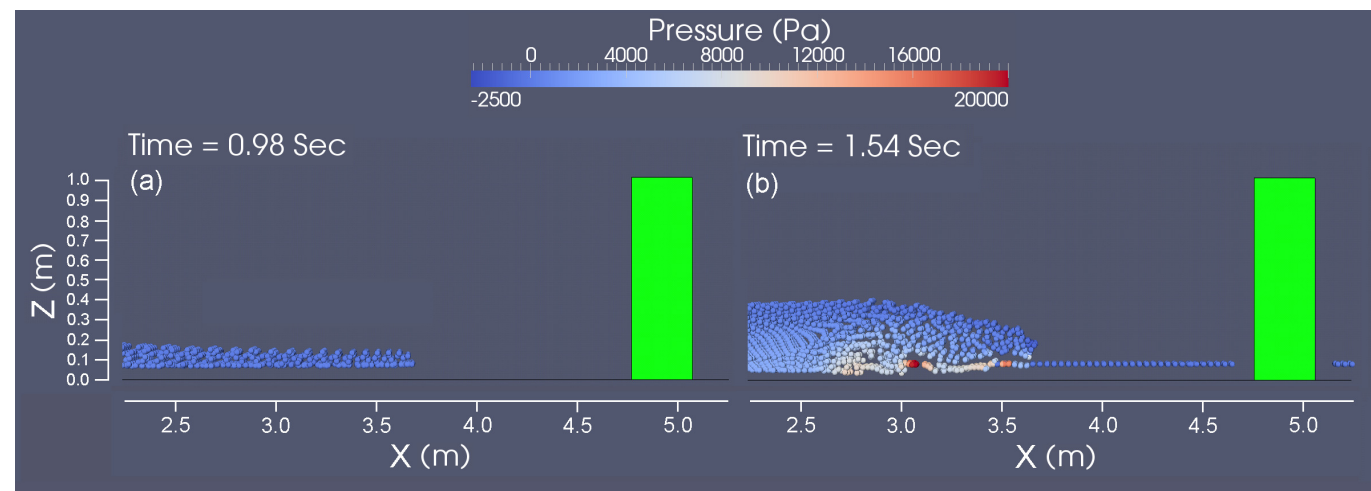

Figure 14. Side view of the bore-front propagating over (a) dry $\left(h_{d}=0\right)$ and (b) wet $\left(h_{d} \approx 0.080 \mathrm{~m}\right)$ beds with $h_{u}$ $=0.85 \mathrm{~m}$ (St-Germain et al., 2012).

\section{Kleefsman et al. (2005)}

As previously mentioned, the primary goal of incorporating the results of this experiment in the present study was to investigate the influence of particle resolution on the "numerical viscosity" associated with the Riemann solver. The later was used to remove inaccuracies observed in the calculated pressure field. The lack of water splashing at initial impact of the hydraulic bore with the structure is believed to be the main manifestation of this excessive numerical viscosity.

Water surface elevation. Compared to the initial water splash observed in the physical experiment (Fig. 17-d), Fig. 15 shows that the numerical reproduction of such splash is considerably improved as the particle resolution is increased (i.e. smaller inter-particle spacing $\Delta$ ). For $\Delta=0.0350 \mathrm{~m}$ (Fig. 17-a), which is the same spacing that was adopted in simulating the main experiments (Nistor $e t$ al. 2010) of this study, splashing is virtually inexistent. This provides a clear explanation for the lack of splashing previously observed in Fig. 9-a. Nevertheless, the splashing observed in the physical experiment (Fig. 17-d) is still more significant, and an even smaller initial inter-particle spacing would be required to reproduce it exactly.

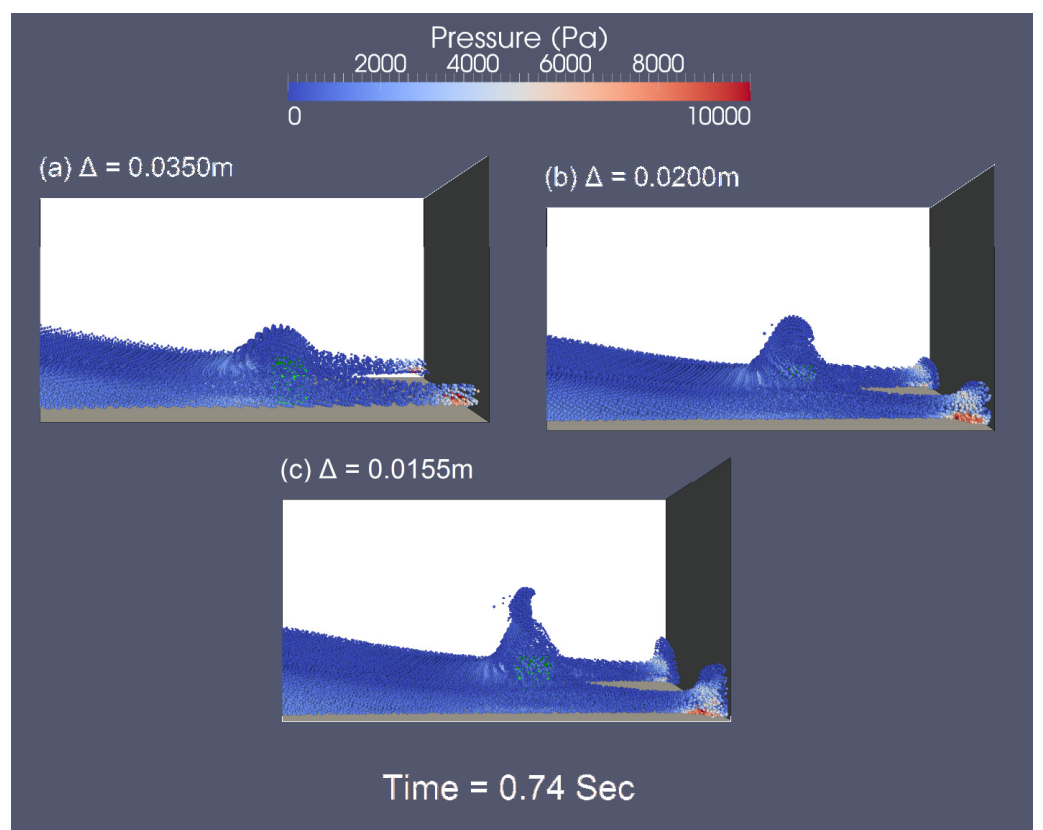

Figure 15. Numerically-reproduced water splash at initial wave impact for inter-particle spacing $(\Delta)$ of (a) 0.0350, (b) 0.0200 , and (c) $0.0155 \mathrm{~m}$, corresponding to simulations B-0350, B-0200, and B-0155, respectively.

With respect to the particle resolution, the convergence of the water surface elevation at wave gauges W1, W2, W3, and W4 is shown in Fig. 16. It can be observed that the time-history of the water surface elevation for the smallest spacing $\Delta=0.0155 \mathrm{~m}$ is better reproduced as peaks are generally higher with a more sudden rise. 

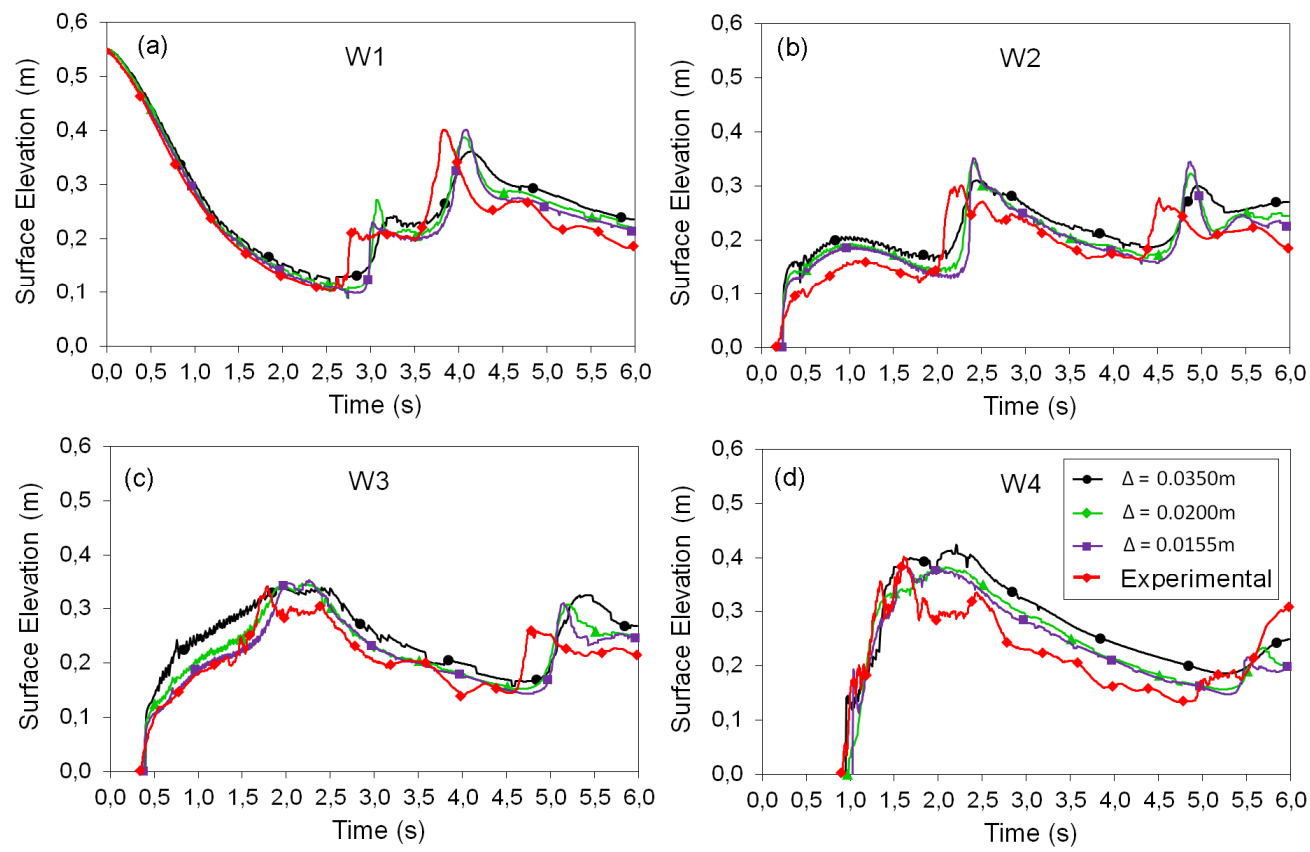

Figure 16. Comparison of numerical (simulations B-0350, B-0200, and B-0155) and experimental (Kleefsman, 2005) time-history of the water surface elevation at wave gauges (a) W1, (b) W2, (c) W3, and (d) W4.

Considering the numerical simulation with $\Delta=0.0155 \mathrm{~m}$ for the comparison with physical results in Fig. 16, relatively good agreement is observed magnitude-wise. However, time lag between experimental and numerical results, varying from 0.21 to 0.36 seconds, is observed as the flow propagates back upstream after reflecting on the downstream wall of the tank. Such flow reflection is shown in Fig. 17, which compares still frames of the simulation with the largest resolution $(\Delta=$ $0.0155 \mathrm{~m}$ ) to the experimental ones. At W1 (Fig. 16-a), the first sudden rise in the water surface elevation is due to the abrupt front of the bore resulting from the reflection on the downstream wall (Fig. 17-i). The time lag in the arrival of this reflected bore is of 0.21 seconds. As this bore then reflects on the upstream wall, the water elevation suddenly rises again in the reservoir, generating the second peak shown in Fig. 16-a. The corresponding time lag has slightly increased to 0.25 seconds. At W2 and W3 (Fig. 16-b and Fig. 16-c, respectively), the second sudden rise in the time-history of the water surface elevation shows that, as the wave resulting from the reflection with the upstream wall arrives at the location of these wave gauges, the time lag has further increased to approximately 0.36 seconds. Hence, this discrepancy in the propagation of the reflected wave increases over time. Such lag in the time-history of the water surface elevation has also been observed in previous studies in which the experiment of Kleefsman et al. (2005) was reproduced numerically using SPH models. Reproducing the physical experiment with both WCSPH and ISPH models, Lee et al. (2010) attributed this discrepancy to the coarse particle resolution they employed $(\Delta=0.0183 \mathrm{~m})$. However, even with the convergence of the reflected wave arrival time observed in Fig. 16-c, the time lag is still present for the smaller $\Delta$ value adopted in the current research. Based on the numerical results of Lee et al. (2010) and the ones obtained in this research, it seems that this discrepancy is neither associated with the particle resolution or the compressibility of the simulated fluid (i.e. compressible or incompressible). Furthermore, as Lee et al. (2010) did not employ a Riemann solver, the discrepancy cannot be associated with this particular solution approach either.

Exerted pressures. In contrast to the water surface elevation, Fig. 18 shows that the overall timehistories of pressure on the front and top faces of the obstacle are not significantly improved with further increases in particle resolution. At initial wave impact however, the pressure impulse at transducer P1 is higher for $\Delta=0.0155 \mathrm{~m}$. This difference is perhaps due to the fact that the numerical outputs of this simulation were obtained at a frequency of $200 \mathrm{~Hz}$ compared to $100 \mathrm{~Hz}$ in the case of the other two. Moreover, in the case of the pressure transducers located on top of the obstacle (P5 and P7) small pressure peaks at approximately 5.25 seconds develop as the particle resolution increases. From Fig. 17-m, these peaks occur because, after reflection on the upstream wall, the numerical wave breaks 


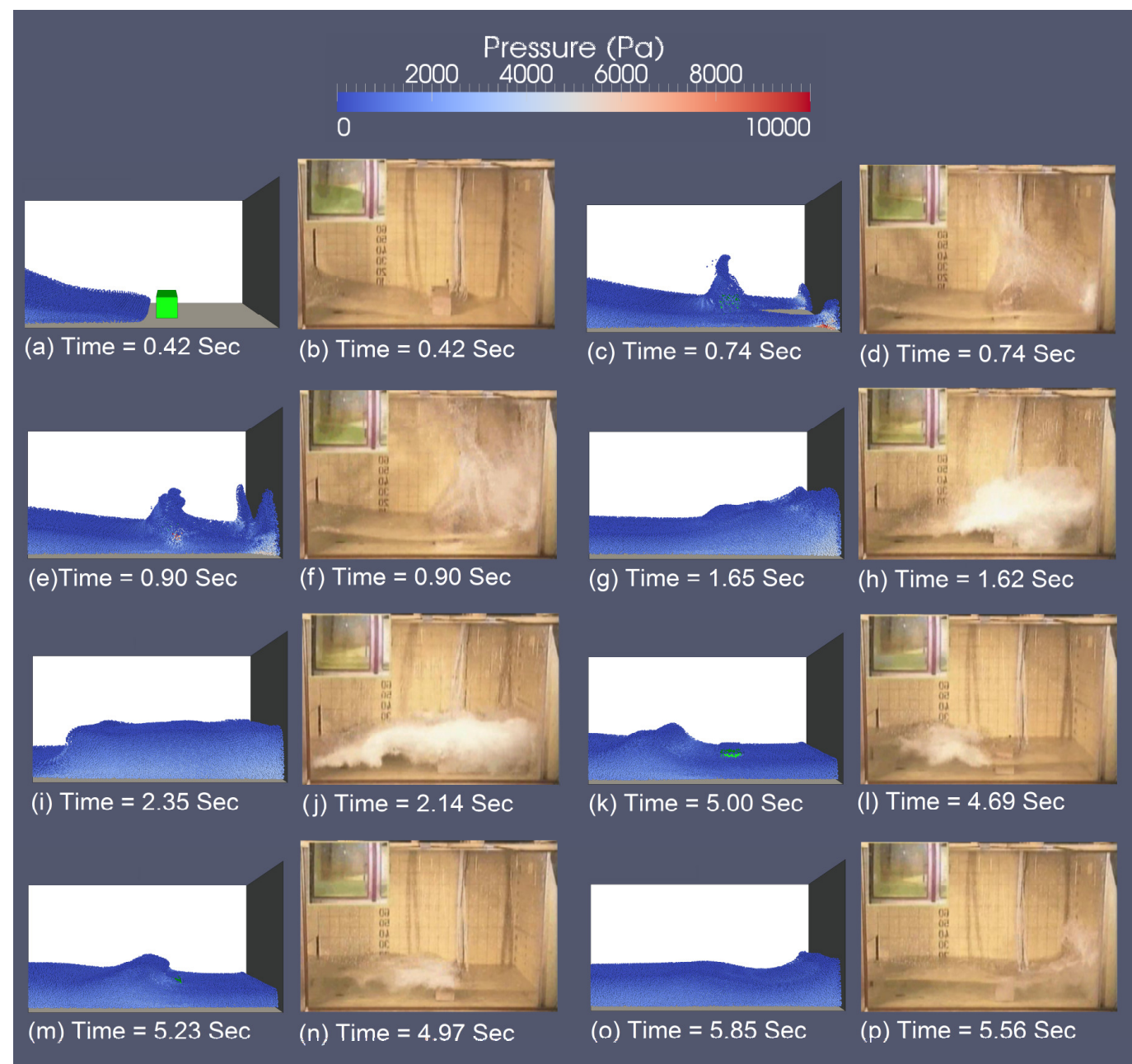

Figure 17. Qualitative comparison of numerical (left, simulation B-0155) and experimental (right, Kleefsman et al. (2005)) water surface profiles downstream of the gate.

directly on top of the structure.

Considering the simulation with the highest resolution for the comparison of the numerical timehistories of the pressure with the ones measured experimentally, good agreement can be observed in Fig. 18. As for the time-history of the water surface elevation, time lag is visible for the pressure transducers located at the front of the obstacle (P1 and P3). Such time lag can also be observed in the numerical results of Lee et al. (2010) and Crespo et al. (2011). It was also noted that, on the top of the obstacle (pressure transducers P5 to P7), no peaks in the pressure were recorded in the physical experiment. The still frames shown in Fig. 17 demonstrate that, after the reflection with the upstream wall, the experimental wave breaks before reaching the obstacle (Fig. 17-1). However, in the numerical simulation (Fig. 17-m), the wave breaks directly on top of it. Lastly, in the study of Crespo et al. (2011), their SPH numerical model also over-predicted the initial impact pressure at transducer P1 (Fig. $18-a)$.

\section{CONCLUSIONS}

Large-scale experimental results of the violent impact of tsunami-like hydraulic bores with a freestanding square column were successfully simulated by employing a single-phase three-dimensional weakly compressible Smoothed Particle Hydrodynamics (WCSPH) numerical model.The main discrepancy observed was that the impulsive impact forces predicted by the numerical model were not recorded in the experimental time-histories of the net base horizontal force acting on the column (Fig. $11)$. As a thin water layer $\left(h_{d} \approx 0.005 \mathrm{~m}\right)$ was present downstream of the gate in most laboratory tests, it was hypothesized that, due to the turbulence associated with the momentum transfer from the advancing 

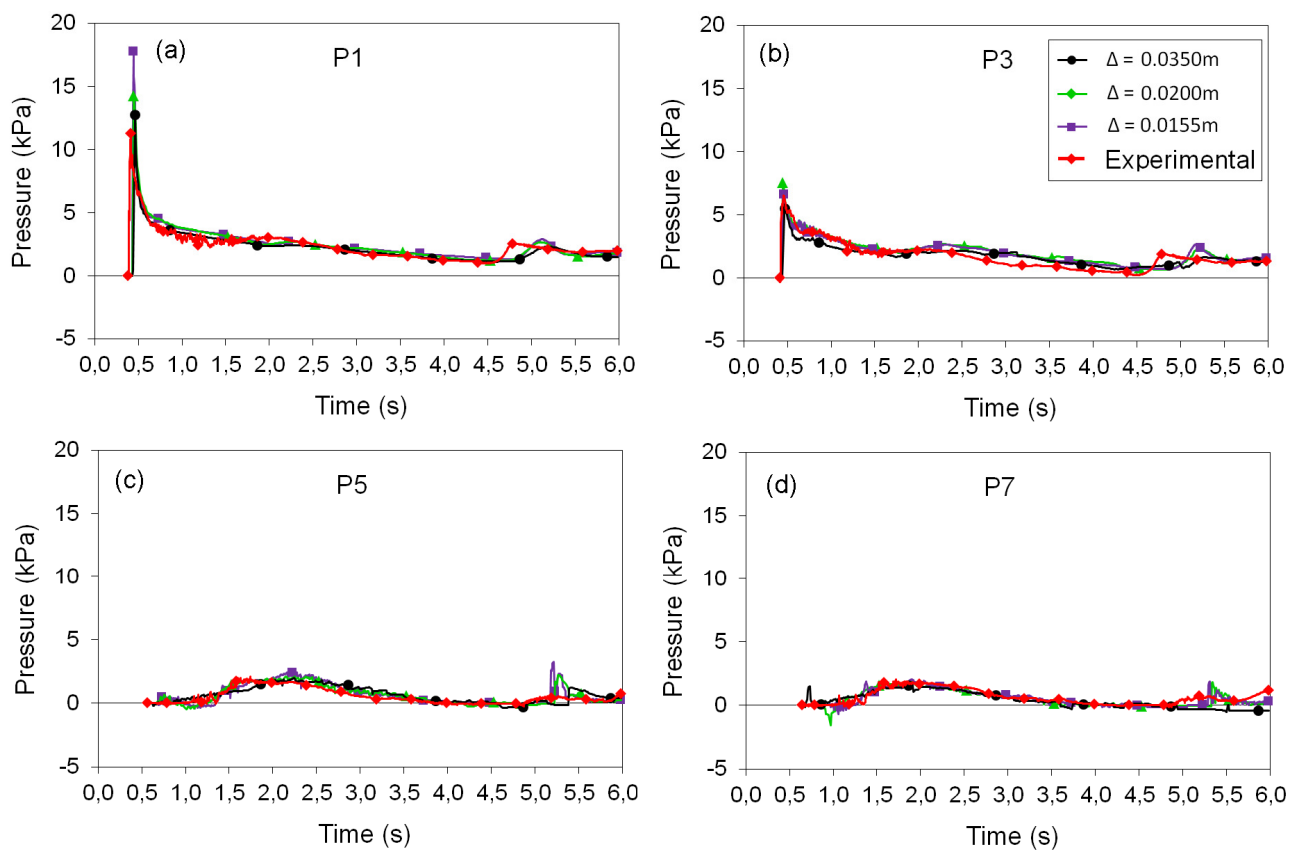

Figure 18. Comparison of numerical (simulations B-0350, B-0200, and B-0155) and experimental (Kleefsman, 2005) time-history of the pressure at pressure transducers (a) P1, (b) P3, (c) P5, and (d) P7.

bore-front to this still water layer, considerable air entrainment occurred. It is well documented in the literature related to breaking wave impacts that entrapped air bubbles can significantly inhibit impulsive shock pressures at the initial impingement of the water with the structure (Peregrine, 2003).

To prevent the large fluctuations observed in the pressure field which are usually associated with WCSPH models, a Riemann solver-based SPH formulation was employed. Although this approach proved to be successful, when estimating impact forces on structures, it introduced excessive "numerical viscosity" in the computations. Such numerical diffusion made the simulations of complex flow features more difficult. However, as it was demonstrated using the physical experiment of Kleefsman et al. (2005), this detrimental side effect can be mitigated by increasing the particle resolution in the numerical simulation.

\section{ACKNOWLEDGMENTS}

This study is part of a comprehensive research program aimed to developing new design guidelines for onshore structures that may be exposed to tsunami-induced loading. The study was funded by the National Sciences and Engineering Research Council of Canada through the NSERC Discovery Grant. The authors also wish to acknowledge the contribution of Mr. Taofiq Al-Faesly, graduate student at the University of Ottawa who performed the part of the physical experiments used in this paper.

\section{REFERENCES}

Batchelor, G.K. 1967. An Introduction to Fluid Dynamics, Prentice-Hall, Englewood Cliffs, Cambridge University Press, Cambridge, United Kingdom, 615 pp.

Chanson, H. 2006. Tsunami surges on dry coastal plains: application of dam break equations, Coastal Engineering Journal, JSCE, 48(4), 355-370.

Crespo, A.J.C., J.M. Dominguez, A. Barreiro, M. Gómez-Gesteira, and B.D. Rogers. 2011. GPUs, a new tool of acceleration in CFD: efficiency and reliability on smoothed particle hydrodynamics methods, PLoS ONE, 6(6), e20685.

Dalrymple, R.A., and B.D. Rogers. 2006. Numerical modeling of water waves with the SPH method, Coastal Engineering, 53, 141-147.

Gingold, R.A., and J.J. Monaghan. 1977. Smoothed particle hydrodynamics: theory and application to non-spherical stars, Monthly Notices of the Royal Astronomical Society, 181, 375-389. 
Gómez-Gesteira, M., and R.A. Dalrymple. 2004. Using a three-dimensional smoothed particle hydrodynamic method for wave impact on a tall structure, Journal of Waterway, Port, Coastal and Ocean Engineering, 130(2), 63-69.

Gómez-Gesteira, M., B.D. Rogers, R.A. Dalrymple, and A.J.C. Crespo. 2010a. State-of-the-art of classical SPH for free-surface flows, Journal of Hydraulic Research, 48 Extra Issue, 6-27.

Gómez-Gesteira, M., B.D. Rogers, R.A. Dalrymple, A.J.C. Crespo, and M. Narayanaswamy. 2010b. User guide for the SPHysics code v2.0, Available at: http://www.sphysics.org.

Hattori, M., A. Arami, and T. Yui. 1994. Wave impact pressure on vertical walls under breaking waves of various types, Coastal Engineering, 22, 79-114.

Hirsh, C. 1998. Numerical computation of internal and external flows, John Wiley \& Sons, New York, $538 \mathrm{pp}$.

Hughes, J.P., and D.I. Graham. 2010. Comparison of incompressible and weakly-compressible SPH for free-surface flows, Journal of Hydraulic Research, 48 Extra Issue, 105-117.

Jánosi, I.M., D. Jan, K.G. Szabó, and T. Tél. 2004. Turbulent drag reduction in dam-break flows, Experiments in Fluids, 37(2), 219-229

Kleefsman, K.M.T., G. Fekken, A.E.P. Veldman, B. Iwanowski, and B. Buchner. 2005. A volume-offluid based simulation method for wave impact problems, J. of Comp. Physics, 206(1), 363-393.

Lauber, G., and W.H. Hager. 1998. Experiments to dam-break wave: horizontal channel, Journal of Hydraulic Research, 36(3), 291-307.

Leal, J.G.A.B., R.M.L. Ferreira, and A.H. Cardoso. 2006. Dam-break wave-front celerity, Journal of Hydraulic Engineering, 132(1), 69-76.

Lee, E.-S., D. Violeau, R. Issa, and S. Ploix. 2010. Application of weakly compressible and truly incompressible SPH to 3-D water collapse in waterworks, Journal of Hydraulic research, 48 Extra Issue, 50-60.

Lucy, L.B. 1977. A numerical approach to the testing of the fission hypothesis, The Astronomical Journal, 82, 1013-1024.

Nistor, I., D. Palermo, Y. Nouri, T. Murty, and M. Saatcioglu. 2009. "Tsunami forces on structures" in Handbook of Coastal and Ocean Engineering, ed. Y.C. Kim, World Scientific, Singapore, 261286.

Nistor, I., D. Palermo, A. Cornett, and T. Al-Faesly. 2010. Experimental and numerical modeling of tsunami loading on structures, Proceedings of $32^{\text {th }}$ International Conference on Coastal Engineering, ASCE, CD-ROM.

Monaghan, J.J. 1994. Simulating free surface flows with SPH, J. of Comp. Physics, 110, 399-406.

Monaghan, J.J., and A. Kos. 1999. Solitary waves on a Cretan beach, Journal of Waterway, Port, Coastal and Ocean Engineering, 125(3), 145-154.

Parshikov, A.N. 1999. Application of a solution of the Riemann problem to the SPH method, Computational Mathematics and Mathematical Physics, 39(7), 1173-1182.

Peregrine, D.H. 2003. Water-wave impact on walls, Annual Review of Fluids Mechanics, 35, 23-43.

Rogers, B.D., and R.A. Dalrymple. 2008. "SPH modeling of tsunami waves" in Advanced Numerical Models for tsunami waves and runup, ed. P.L. Liu, H. Yeh, and C. Synolakis, Advances in Coastal and Ocean Engineering, World Scientific, Vol. 10, 75-100.

Shadloo, M.S., A. Zainali, M. Yildiz, and A. Suleman. 2011. A robust weakly compressible SPH method and its comparison with an incompressible SPH, International Journal for Numerical Methods in Engineering, 89(8), 939-956.

Silvester, T.B., and P.W. Cleary. 2006. Wave-structure interaction using smoothed particle hydrodynamics, Proceedings of 5th CSIRO International Conference on CFD in the Process Industries, CD-ROM.

St-Germain, P., I. Nistor, and R. Townsend. 2012. Numerical modeling of the impact with structures of tsunami bores propagating on dry and wet beds using the SPH method, International Journal of Protective Structures, 3(2), 221-256.

Stansby, P.K., A. Chegini, and T.C.D. Barnes. 1998. The initial stages of dam-break flow, Journal of Fluid Mechanics, 374, 407-242.

Toro, E.F., M. Spruce, and W. Speares. 1994. Restoration of the contact surface in the HLL-Riemann solver, Shock Waves, 4, 25-34.

Toro, E.F. 2001. Shock capturing methods for free surface shallow flows, John Wiley \& Sons, New York, 309 pp. 